\title{
Matematik Derslerinde Matematik Tarihi Kullanımının Matematik Tutumuna Etkisi*
}

\author{
Kani BAŞIBÜYÜK, Yasin SOYLU**
}

Matematik Derslerinde Matematik Tarihi Kullanımının Matematik Tutumuna Etkisi

\section{Özet}

Bu çalışmada, matematik derslerinde matematik tarihi kullanımının öğrencilerin matematiğe olan tutumlarına etkisi incelenmiştir. Araştırmada verilerin elde edilmesi sürecinde deneysel desenlerden yarı deneysel desen olarak değerlendirilen ön test/son test eşitlenmemiş kontrol gruplu model kullanılmıştır. Araştırma, Erzincan ilinde bir ortaokulda farklı iki şubede bulunan 39 sekizinci sınıf öğrencisi ve bir ortaokul matematik öğretmeni ile gerçekleştirilmiştir. Çalışmada öğrencilerin matematik tarihi uygulamaları sonucunda matematiğe yönelik tutumlarındaki değişimi incelemek için ortaokul öğrencilerinin matematik tutumlarını incelemeyi amaçlayan ölçek kullanılmıştır. Elde edilen veriler Statistical Package for Social Sciences (SPSS 18) programı kullanılarak analiz edilmiştir. Verilerin analizinde normallik testi sonuçlarına göre ilgili testler kullanımış ve gerekli değerlendirmelerde bulunulmuştur. Matematik tutumu ilgi, kaygı, çalışma ve gereklilik olmak üzere dört faktör altında toplanmışır. Bulgular incelendiğinde matematik tarihi uygulamalarının matematik dersine yönelik tutumu olumlu yönde etkilediği anlaşılmaktadır.

Anahtar Kelimeler: Matematik Tarihi, Matematik Tutum, Sekizinci Sını Öğrencileri
The Effect of Using History of Mathematics in Mathematics Lessons on Mathematics Attitude

\section{Abstract}

In this study, the effect of the use of mathematical history in mathematics lessons on students' attitudes towards mathematics was examined. In the process of obtaining data in the study, pre-test/post-test unequal control group model, which is evaluated as a semi-experimental design from experimental designs, was used. The research was conducted with 39 eighthgrade students and a middle school mathematics teacher in two different branches in a secondary school in Erzincan. As a result of students applying mathematical history in the study, a scale was used to examine the math attitudes of middle school students in order to examine the change in attitudes towards mathematics. The obtained data were analyzed using the Statistical Package for Social Sciences (SPSS 18) program. In the analysis of the data, related tests were used according to normality test results and necessary evaluations were made. Mathematical attitude has been gathered under four factors as interest, anxiety, work and necessity. When the findings are examined, it is understood that applying the history of mathematics affects the attitude toward mathematics course positively.

Key Words: History of Mathematics, Mathematics Attitude, Eighth Grade Students

\section{Giriş}

Matematik öğretimi, kişiye günlük hayatta karşılaşabileceği problemleri çözmesi için gerekli olan bilgi ve becerileri kazandırmayı amaç edinmiştir. Dolayısı ile öğrencilerin matematiği sevmesi

\footnotetext{
${ }^{*}$ Bu çalışma birinci yazarın doktora tezinin bir kısmından oluşmaktadır.

**Kani BAŞIBÜYÜK, Dr. Öğr. Üyesi, Erzincan Üniversitesi, Refahiye Meslek Yüksekokulu. ORCID ID orcid.org/0000-00020477-7349, Yasin SOYLU, Prof. Dr. Atatürk Üniversitesi, Kazım Karabekir Eğitim Fakültesi ORCID ID orcid.org/00000003-0906-4994
} 
ve onu korku veren bir uğraş olarak görmemesi matematiğin etkili öğrenimi açsından önem arz etmektedir (Altun, 2006; Altun, 2008). Öğrencilerin matematiği öğrenirken keyif alması ve bilgiyi kendi kurdukları şematik yapıya göre oluşturmaları kalıcı ve etkili öğrenmeyi ortaya çıkarır (Baykul, 2009; Saban, 2005; Skemp, 1986). Bunun için de öğrencilerin farklı bakış açılarını ve matematiğin değişik yanlarını ortaya çıkaracak, öğrencilerin matematiğe karşı olumlu tutum geliştirmesini sağlayacak yaklaşımlara ihtiyaç vardır. Bu yaklaşımlardan biri de matematik öğretiminde matematik tarihinin kullanımasıdır. Matematik tarihi matematikçilerin hayatları ve yaptıkları çalışmalardan belirli kesitler sunan ayrıca karşılaşılan problemlerin çözümüne dair bilgiler veren bilimsel bir alandır. Farklı bir ifade ile matematik tarihi, matematiksel bilginin medeniyetler boyunca gelişimini ve bu gelişim çerçevesinde nasıl büyüdüğünü ele alarak bilgiler sunan bir bilim olarak ifade edilebilir (Baki, 2008; Yıldız, 2013). Matematik tarihi, matematiğin temel yapı taşlarının öğrenilmesi, matematiğin felsefi yönünün ortaya çıkarılması, matematiğin sosyal ve kültürel yönüne vurgu yapması ve ünlü matematikçilerin hayatlarından önemli kesitler sunarak öğrencilere ilham kaynağı olmasından dolayı matematik öğretiminde önem arz etmektedir (Baki, 2008; Burns, 2010; Guillemette, 2017; Gürsoy, 2010; Harverhals \& Matt, 2010; Lewis, 2016; Pepe \& Guerraggio, 2017).

Yarı deneyselcilik felsefesinin dayandığı temel kaynaklardan biri olan Lakatos'un matematiksel bilginin gelişim modeli, merkezine matematik tarihini koymuştur. Lakatos matematiğin, kendi tarihinden soyutlanmaması gerektiğini ifade etmiştir. Tarihsel bir süreç içerisinde gelişen ve değişime uğrayan matematiğin, matematikçiler tarafından geliştirildiği unutulmamalı ve matematikçiler arasında kullanılan bir dil olarak değerlendirilmesi gerekmektedir (Baki, 2008; Bayam, 2014). Matematiğin ortaya çıkış amacının, matematikteki insan faktörünün, matematiksel düşünme yollarının ve matematiğin sosyo-kültürel boyutunun ifade edilebilmesinde matematik tarihi aydınlatıcı bir unsurdur (Ernest, 2004). Davis, Hersh ve Marchisotto (2012) sınıf ortamında keşfetme ve icat etme isteklerini ortaya çıkaran öğrenciye farklı bakış açıları kazandıran felsefi görüşler üzerinde durmuşlardır.

Amerika'da bulunan The National Council of Teachers of Mathematics (NCTM) matematik tarihinin matematik öğretimine entegre edilmesi gerektiğini vurgulamıştır. Matematiğin insanlık tarihi için büyük bir başarı olduğunu ve bu başarının arkasındaki kültürel etmenlerin de ortaya çıkarılması gerektiğini belirtmiştir. Peki, matematik tarihinin matematik öğretiminde kullanılması noktasında ne tür görüşler vardır? (NCTM, 2000) matematik tarihinin matematik öğretiminde kullanılmasının nedenlerini beş başılı halinde aşağıda görüldüğü gibi ifade etmiştir:

1. Motivasyonu artırmak ve matematiğe karşı daha olumlu bir yaklaşım oluşturma;

2. Geçmiş dönemlerde matematiğin gelişmesine engel durumları görerek şu zamandaki matematik öğrenmenin zorluklarını anlama;

3. Tarihsel kaynaklardan yararlanarak, matematiksel bilgiye karşı bakış açısı geliştirmede insan faktörünü görme; 
4. Tarih öğrenmeye rehberlik eder;

5. Tarihsel problemler öğrencilerin matematiksel düşünmelerini geliştirir.

Matematik tarihi, öğrencilerin matematiğe karşı bakış açılarını genişletmesinin yanında öğrencilerin zihninde farklı ufuklar da açmaktadır (Miller, 2002). Aynı şekilde öğretmenler açısından da matematiksel kavramların derinlemesine algılanıp öğrencilere aktarılması önem arz etmektedir. Öğretmen ve öğrencilerde tarihsel süreçler içerisinde gelişen ve değişen matematiksel kavramları araştırma, kültürel ve sosyolojik bakış açısıyla olayları değerlendirme algısı oluşması açısından da matematik tarihi önemlidir. Öğrenme sürecinin başında bulunan öğrenciler için, Pisagor'un yaşadığı yerden ayrılarak matematik öğrenmek için yaptığı yolculuk, Harizmi'nin kendi dönemi itibari ile üst düzey sayılabilecek cebirsel ifadeleri kullanmış olması, Mısırlıların çok eski dönemlerde yaşamış olmalarına rağmen üst düzey matematiksel sırları barındıran piramitleri inşa etmiş olmaları, bugün kullandığımız sayı sistemlerinin çoğunun binlerce yıl öncesindeki medeniyetler tarafından bulunduğu vb. hikayeler, öğrencilerin matematiğe karşı daha çok saygı duymalarını ve onun önemini anlamalarını sağlayacaktır (Clark \& Thoo, 2014; Fried, 2007; Furinghetti, 2004; Heiede, 1992; Mann, 2011). Bu bağlamda bu çalışmada, matematik derslerinde matematik tarihi kullanımının öğrencilerin matematiğe olan tutumlarına etkisi incelenmiştir.

Bu konuda yapılan çalışmalar (Albayrak, 2011; Bell, 1992; Cheung, 2014; Ersoy \& Öksüz, 2016; Goodwin, 2007; Gönülateş, 2004; Gürsoy, 2010; Horton, 2011; İdikurt, 2007; Lim \& Chapman, 2015; Mcbride, 1974; Siu, 2007; Yevdokimov, 2007) genel olarak incelendiğinde; matematik tarihinin matematik öğretiminde kullanımı konusunda son yıllarda önemli bir artış olduğu görülmektedir. Çalışmalarda öne çıkan değişkenler matematiğe olan tutum ve matematik başarısıdır. Çalışmalarda bu değişkenlere ait sonuçlar farklılık göstermektedir. Görüşme verilerinde öğrenci, öğretmen adayı ve öğretmenler matematik tarihinin matematik öğretiminde kullanılması noktasında olumlu görüş belirttikleri görülmüştür. Ayrıca yine çalışma grubunda bulunan kişilerin matematik tarihi uygulamalarıyla derslerde fazla karşılaşmadıkları ve kullanmadıkları anlaşılmaktadır. Öğretmenlerle yapılan çalışmalarda öğretmenlerin matematik tarihi bilgilerinin zayıf olduğu ortaya çıkmıştır. Bu olumsuz durumlara sebep olan nedenlerden öğretim programlarında matematik tarihine önem verilmemesi ve öğretmenlerin matematik tarihini önemsememeleri ön plana çıkmaktadır. Türkiye'de bu konuda yapılan çalışmalar yurt dışında yapılan çalışmalarla kıyaslandığında sayısal olarak bir eksikliğin söz konusu olduğu görülmektedir. Yurt içinde ve yurt dışındaki çalışmalarda uygulama sürecinde ve sonrasında öğrenci ve öğretmeni birlikte sürece dahil eden çalışmalar yok denecek kadar azdır. Dolayısı ile daha kapsamlı bir bakış açısı kazanabilmek ve derinlemesine bir değerlendirme yapabilmek için öğrenci, öğretmen ve araştırmacının bu süreçte birlikte bulunabileceği çaıışmalara intiyaç vardır. Literatüre bakıldığında konu ile ilgili birçok çalışma görülmektedir. Ancak yapılan çalışmaların çoğunda, matematik tarihinin konu ile ilgisi gözetilmeksizin bir süre uygulanmış ve bunun yansımaları ele alınmıştır. Bu çalışmada ise belli bir sistematik içerisinde konu ile ilgili kısımlarda ve gerekli durumlarda matematik tarihine yer verilmiştir, yani matematik tarihi ilgili konu içerisine serpiştirilmiştir, bu durum çalışmayı farklı kılan etmenlerden biridir. Çalışmayı farklı kılan etmenlerden biri de matematik tutumunun faktör başlıkları altında değerlendirilmesi ve bu 
Kani BAŞIBÜYÜK | Yasin SOYLU

noktada derinlemesine bir bakış açısı kazanıımış olmasıdır. Çalışmanın bir diğer özelliği ise etkinliklerin öğretmen tarafından sınıf ortamında sunulmasıdır. Dolayısı ile öğretmen bizzat sürecin içerisinde yer alarak konu ile ilgili daha objektif bir bakış açısı kazanmıştır.

\section{Yöntem}

Bu araştırmada verilerin elde edilmesi sürecinde deneysel desenlerden yarı deneysel desen olarak değerlendirilen ön test/son test eşitlenmemiş kontrol gruplu model kullanılmıştır. Bu modelde başlangıçta atama yapılmayan grupların hangisinin kontrol hangisinin deney grubu olacağına yansız atama yoluyla karar verilir. Modelde bir kontrol bir deney olmak üzere iki grup vardır. Her iki gruba ön test uygulanır. Daha sonra deney grubuna uygulama sürecinde belirli işlemler uygulanır ve her iki gruba son test uygulanır (Metin, 2015). Çalışma bir okulda bulunan iki sekizinci sınıf şubesinde yapıldığından ve uygulama süreci de dersleri kapsadığı için bu desenin kullanılması uygun görülmüştür. Bu çalışmada deney ve kontrol grubu oluşturma sürecinde hâlihazırda bulunan iki sınıf deney ve kontrol grubu olarak değerlendirilmiştir. Ancak hangi grubun deney ve kontrol grubu olacağına seçkisiz atama ile karar verilmiştir.

Bu araştırma, Erzincan ilinde bir ortaokulda farklı iki şubede bulunan 39 sekizinci sınıf öğrencisi ve bir ortaokul matematik öğretmeni ile gerçekleştirilmiştir. Araştırma grubunun belirlenmesinde uygun örnekleme yöntemi benimsenmiştir. Uygun örnekleme, zaman para ve işgücü kaybını önlemeyi amaç edinen ve en ulaşlabilir örneklemi oluşturmayı hedefleyen örnekleme türüdür. Uygun örneklemedeki amaç, araştırmacının çalışılan konu ile ilgili kapsamlı ve en kolay ulaşılabilir ortamların dizaynıdır (Büyüköztürk vd., 2010; Yıldııı \& Şimşek, 2011). Bu çalışmada da uygulama okulunun araştırmacının sürekli ulaşabileceği ve irtibat kurabileceği bir konumda olmasından dolayı uygun örnekleme yöntemi kullanılmıştır.

Araştırmacının seçmiş olduğu okulda iki şube (19 ve 20 kişi) bulunmaktadır. Ayrıca okulun, araştırmacı için ulaşım noktasında elverişli bir konumda olması da bu okulun seçilmesindeki diğer bir etkendir. Araştırmada çalışılan öğretmen, İlköğretim Matematik Öğretmenliği mezunu olup, üç yıllık bir deneyime sahip bir öğretmendir. Hâlihazırdaki eğitim durumu ise yüksek lisans düzeyindedir. Araştırmaya katılan öğretmen lisans düzeyinde Matematik Tarihi dersi almıştır. Lisans eğitimi sonrasında matematik tarihi ile ilgili herhangi bir etkinliğe katılmamıştır. Ayrıca araştırmanın yürütülebilmesi için Erzincan II Milli Eğitim Müdürlüğünden gerekli izinler alınmıştır. Uygulamada kullanılan etkinlikler cebir ve sayılar konularına ait etkinliklerdir dolayısı ile her etkinlik ilgili konu dâhilinde uygulanmıştır. Yani uygulama süreci öğretmenin öğretim programını uygulama sürecine ve derste ele alınan konulara göre şekillenmiştir. Uygulamada 15 adet matematik tarihi ile ilgili etkinlik kullanılmıştır.

Çalışmada öğrencilerin matematik tarihi uygulamaları sonucunda matematiğe yönelik tutumlarındaki değişimi incelemek için Önal (2013) tarafından geliştirilmiş olan ortaokul öğrencilerinin matematik tutumlarını incelemeyi amaçlayan ölçek kullanılmıştır. Ölçek maddeleri dört faktör altında toplanmıştır. Bu faktörler; ilgi, kaygı, çalışma ve gereklilik başlıklarından oluşmaktadır. 22 
maddeden oluşan ölçekte "ilgi" için 10 madde, "Kaygı" için 5 madde, "Çalışma" için 4 madde ve "Gereklilik" için 3 madde bulunmaktadır. Elde edilen veriler Statistical Package for Social Sciences (SPSS 18) programı kullanılarak analiz edilmiştir. Verilerin analizinde normallik testi sonuçlarına göre ilgili testler kullanılmış ve gerekli değerlendirmelerde bulunulmuştur.

\section{Bulgular ve Yorum}

Bu bölümde elde edilen veriler doğrultusunda gerekli analizler yapılmış ve yorumlanmıştır. Normallik testi yapıldıktan sonra, grupların ön test ve son test verileri analiz edilmiştir.

Öğrencilerin matematik başarı testi ön test puanları açısından deney ve kontrol grupları arasında anlamlı düzeyde bir farklıık olup olmadığını tespit etmek için öncelikle normallik testi yapılmış olup Shapiro-Wilk testi sonuçlarına göre grupların matematik başarı testi ön test puanlarının normal dağılım göstermediği belirlenmiştir $(p<0.05)$. Bu doğrultuda deney ve kontrol grupları arasında karşılaştırma yapabilmek için parametrik olmayan testlerden Mann Whitney-U testi kullanılmıştır. İlgili bulgular Tablo 1'de verilmiştir.

Tablo 1. Deney ve Kontrol Gruplarının Matematiğe Yönelik ilgi Faktörü Son Test Puanlarına iliş̧kin Sonuçlar

\begin{tabular}{lccccc}
\hline \hline & $N$ & Sira Ortalaması & Sira Toplamı & $U$ & $p$ \\
\hline Kontrol Grubu & 19 & 19.71 & 374.50 & 184.500 & .876 \\
Deney Grubu & 20 & 20.28 & 405.50 & & \\
Toplam & 39 & & & & \\
\hline
\end{tabular}

Tablo 1 incelendiğinde deney ve kontrol gruplarının matematik başarısı ön test puanları arasında istatistiksel olarak anlamlı düzeyde bir farklılık olmadığı görülmektedir ( $U=184.50$ p>0.05). Yani deney ve kontrol gruplarının başarı yönünden denk gruplar olduğu söylenebilir.

\subsection{Matematiğe Yönelik Ilgi Faktörüne ilişkin Bulgular}

Bu bölümde MTÖ’den elde edilen puanlara bağlı olarak öğrencilerin ilgi faktörüne ilişkin puanlarının değerlendirilmesi yapılmıştır.

Öğrencilerin matematiğe yönelik ilgi faktörü son test puanları açısından deney ve kontrol grupları arasında anlamlı düzeyde bir farklılık olup olmadığını tespit etmek için öncelikle normallik testi yapılmış olup Shapiro-Wilk testi sonuçlarına göre grupların matematiğe yönelik ilgi faktörü son test puanlarının normal dağılım göstermediği belirlenmiştir ( $p<0.05)$. Bu doğrultuda deney ve kontrol grupları arasında karşılaştırma yapabilmek için non-parametrik testlerden Mann Whitney-U testi kullanılmıştır. İlgili bulgular Tablo 2'de verilmiştir. 
Kani BAŞIBÜYÜK | Yasin SOYLU

Tablo 2. Deney ve Kontrol Gruplarının Matematiğe Yönelik Ilgi Faktörü Son Test Puanlarına İlişkin Sonuçlar

\begin{tabular}{lcccccc}
\hline \hline & $N$ & Sira Ortalaması & Sira Toplamı & $U$ & $P$ & $R$ \\
\hline Kontrol Grubu & 19 & 14.32 & 272.00 & 82.000 & .002 & 0.487 \\
Deney Grubu & 20 & 25.40 & 508.00 & & & \\
Toplam & 39 & & & & & \\
\hline
\end{tabular}

Tablo 2 incelendiğinde deney ve kontrol gruplarının matematiğe yönelik ilgi faktörü son test puanları arasında istatistiksel olarak anlamlı düzeyde bir farklıık olduğu görülmektedir $(\mathrm{U}=82$, $\mathrm{p}<0.05)$. Buradan hareketle, öğrencilerin başlangıçta matematiğe olan ilgilerinin benzer düzeyde iken yapılan uygulamalar sonrasında deney grubunda matematiğe olan ilginin kontrol grubuna göre istatistiksel olarak anlamlı düzeyde arttığı sonucuna varılabilir.

\subsection{Matematiğe Yönelik Kaygı Faktörüne ilişkin Bulgular}

Bu bölümde MTÖ’den elde edilen puanlara bağlı olarak öğrencilerin kaygı faktörüne ilişkin puanlarının değerlendirilmesi yapılmıştır.

Öğrencilerin matematiğe yönelik kaygı son test puanları açısından deney ve kontrol grupları arasında anlamlı düzeyde bir farklılık olup olmadığını tespit etmek için öncelikle normallik testi yapılmış olup Shapiro-Wilk testi sonuçlarına göre grupların kaygı ön test puanlarının normal dağıım göstermediği belirlenmiştir ( $p<0.05)$. Bu doğrultuda deney ve kontrol grupları arasında karşılaştırma yapabilmek için parametrik olmayan testlerden Mann Whitney-U testi kullanılmıştır. İlgili bulgular Tablo 3'te verilmiştir.

Tablo 3. Deney ve Kontrol Gruplarının Matematiğe Yönelik Kaygı Faktörü Son Test Puanlarına İlişkin Sonuçlar

\begin{tabular}{lccccc}
\hline \hline Grup & $N$ & Sira Ortalaması & Sira Toplamı & $U$ & $P$ \\
\hline Kontrol Grubu & 19 & 22.92 & 435.50 & 134.500 & .117 \\
Deney Grubu & 20 & 17.23 & 344.50 & & \\
Toplam & 39 & & & & \\
\hline
\end{tabular}

Tablo 3 incelendiğinde deney ve kontrol gruplarının matematiğe yönelik kaygı son test puanları arasında istatistiksel olarak anlamlı düzeyde bir farklılık olmadığı görülmektedir ( $U=134.50$, $\mathrm{p}>0.05)$. Buradan, öğrencilerin başlangıçta matematiğe duydukları kaygı düzeylerinin benzer iken yapılan uygulamalar sonrasında deney grubunun matematiğe yönelik duyulan kaygı sıra ortalamalarında azalma gözlenmesine rağmen azalmanın istatistiksel olarak bir önem arz etmediği anlaşılmaktadır. Yani matematik tarihi uygulamaları sonrasında deney grubundaki öğrencilerin kaygı 
düzeylerinde bir azalma olmuştur ama kontrol grubuyla karşılaştııılığında anlamlı bir fark ortaya çıkmamışır.

\subsection{Matematiğe Yönelik Çalışma Faktörüne ilişkin Bulgular}

Bu bölümde MTÖ’den elde edilen puanlara bağıı olarak öğrencilerin çalışma faktörüne ilişkin puanlarının değerlendirilmesi yapılmıştır.

Öğrencilerin matematiğe yönelik çalışma faktörü son test puanları açısından deney ve kontrol grupları arasında anlamlı düzeyde bir farklılık olup olmadığını tespit etmek için öncelikle normallik testi yapılmış olup Shapiro-Wilk testi sonuçlarına göre grupların çalışma faktörü son test puanlarının normal dağıım göstermediği belirlenmiştir ( $p<0.05)$. Bu doğrultuda deney ve kontrol grupları arasında karşılaştırma yapabilmek için parametrik olmayan testlerden Mann Whitney-U testi kullanılmıştır. Il gili bulgular Tablo 4 'te verilmiştir.

Tablo 4. Deney ve Kontrol Gruplarının Matematiğe Yönelik Çalışma Faktörü Son Test Puanlarına iliş̧kin Sonuçlar

\begin{tabular}{lccccc}
\hline \hline Grup & $N$ & Sira Ortalaması & Sira Toplamı & $U$ & $p$ \\
\hline Kontrol Grubu & 19 & 16.63 & 316.00 & \multirow{2}{*}{126.000} & .070 \\
Deney Grubu & 20 & 23.20 & 464.00 & & \\
Toplam & 39 & & & & \\
\hline
\end{tabular}

Tablo 4 incelendiğinde deney ve kontrol gruplarının matematiğe yönelik çalışma faktörü son test puanları arasında istatistiksel olarak anlamlı düzeyde bir farklılık olmadığı görülmektedir (U= $126, p>0.05$ ). Bu durum, öğrencilerin başlangıçta matematiğe yönelik çalışma isteklerinin benzer düzeyde iken yapılan uygulamalar sonrasında çalışma puanları arasındaki farkın istatistiksel olarak anlamlı olmadığı şeklinde yorumlanabilir. Burada anlamlı bir fark ortaya çıkmasa da, deney grubundaki öğrencilerin çalışma faktörüne ilişkin puanlarının sıra ortalamalarının kontrol grubuna göre daha yüksek olduğu görülmektedir $(23.20>16.63)$.

\subsection{Matematiğe Yönelik Gereklilik Faktörüne ilişkin Bulgular}

Bu bölümde MTÖ'den elde edilen puanlara bağlı olarak öğrencilerin gereklilik faktörüne ilişkin puanlarının değerlendirilmesi yapılmıştır.

Öğrencilerin matematiğe yönelik gereklilik son test puanları açısından deney ve kontrol grupları arasında anlamlı düzeyde bir farklılık olup olmadığını tespit etmek için öncelikle normallik testi yapılmış olup Shapiro-Wilk testi sonuçlarına göre grupların gereklilik ön test puanlarının normal dağılım göstermediği belirlenmiştir $(p<0,05)$. Bu doğrultuda deney ve kontrol grupları arasında karşılaştırma yapabilmek için parametrik olmayan testlerden Mann Whitney-U kullanılmıştır. İlgili bulgular Tablo 5'de verilmiştir. 
Kani BAŞIBÜYÜK | Yasin SOYLU

Tablo 5. Deney ve Kontrol Gruplarının Matematiğe Yönelik Gereklilik Faktörü Son Test Puanlarına Iliş̧kin Sonuçlar

\begin{tabular}{lcccccc}
\hline \hline Grup & $N$ & Sira Ortalaması & Sira Toplamı & $U$ & $P$ & $r$ \\
\hline Kontrol Grubu & 19 & 15.16 & 288.00 & 98.000 & .009 & -0.41 \\
Deney Grubu & 20 & 24.60 & 492.00 & & & \\
Toplam & 39 & & & & & \\
\hline
\end{tabular}

Tablo 5 incelendiğinde deney ve kontrol gruplarının matematiğe yönelik gereklilik son test puanları arasında istatistiksel olarak anlamlı düzeyde bir farklılık olduğu görülmektedir ( $U=98$, $\mathrm{p}<0.05)$. Bu değerlere bağlı olarak, matematik tarihi uygulamalarının öğrencilerin matematiğin gerekliliğine olan inançlarını artırdığı sonucu ortaya çıkmaktadır.

\subsection{Matematiğe Yönelik Tutum Toplam Puanlarına ilişkin Bulgular.}

Bu bölümde MTÖ’den elde edilen toplam puanlara bağlı olarak öğrencilerin test puanlarının değerlendirilmesi yapılmıştır.

Öğrencilerin matematiğe yönelik tutum son test toplam puanları açısından deney ve kontrol grupları arasında anlamlı düzeyde bir farklılık olup olmadığını tespit etmek için öncelikle normallik testi yapılmış olup Shapiro-Wilk testi sonuçlarına göre grupların matematiğe yönelik tutum son test puanlarının normal dağılım göstermediği belirlenmiştir $(p<0.05)$. Bu doğrultuda deney ve kontrol grupları arasında karşılaştırma yapabilmek için parametrik olmayan testlerden Mann Whitney-U kullanılmıştır. Illgili bulgular Tablo 6'da verilmiştir.

Tablo 6. Deney ve Kontrol Gruplarının Matematiğe Yönelik Tutum Son Test Puanlarına Illişkin

\begin{tabular}{lcccccc}
\multicolumn{7}{c}{ Sonuçlar } \\
\hline \hline Grup & $N$ & Sira Ortalaması & Sira Toplamı & $U$ & $p$ & $r$ \\
\hline Kontrol Grubu & 19 & 14.63 & 278.00 & 88.000 & .004 & -0.45 \\
Deney Grubu & 20 & 25.10 & 502.00 & & & \\
Toplam & 39 & & & & & \\
\hline
\end{tabular}

Tablo 6 incelendiğinde deney ve kontrol gruplarının matematiğe yönelik tutum son test toplam puanları arasında istatistiksel olarak anlamlı düzeyde bir farklılık olduğu görülmektedir ( $\mathrm{U}=88$, $p<0.05)$. Bu durum öğrencilerin uygulama öncesinde matematiğe yönelik tutum toplam puanlarının benzer düzeyde iken, yapılan uygulamalar sonrasında matematiğe yönelik tutum toplam puan ortalamalarının deney grubu yönünde anlamlı düzeyde arttığı görülmektedir. 


\section{Tartışma, Sonuç ve Öneriler}

Matematik tarihinin matematik tutumuna etkisi MTÖ verilerinden elde edilen bulgulara bağlı olarak değerlendirilmiştir. Matematik tutumu ilgi, kaygı, çalışma ve gereklilik olmak üzere dört faktör altında toplanmıştır. Elde edilen bulgulara göre deney ve kontrol gruplarının matematiğe yönelik ilgi son test puanları arasında istatistiksel olarak anlamlı düzeyde bir farklılık gösterdiği ortaya çıkmıştır. Yani deney grubunun ilgi puanlarının kontrol grubunun ilgi puanlarından anlamlı düzeyde yüksek olduğu sonucuna varılmıştır. Bu değerlendirmelere bağlı olarak matematik tarihi uygulamalarının öğrencilerin matematiğe olan ilgilerini arttırdığı söylenebilir.

Literatüre bakıldığında matematik tarihi ve matematiğe duyulan ilgi değişkenlerini bir arada bulunduran çalışmaların çoğunda (Alparslan, 2011; Burns, 2010; Despeaux, 2014; Fadlelmula, 2015; Gönülateş, 2004; Haile, 2008; Lim \& Chapman, 2015; Marshall, 2000; Mcbride, 1974; Sullivan, 2000; Yevdokimov, 2007) matematik tarihinin matematiğe duyulan ilgi ve motivasyonu olumlu yönde etkilediği ortaya çıkmıştır. Gönülateş (2004) matematik tarihine yönelik uygulamaların öğrencilerin anlamalarında etkili bir araç olduğunu belirtmiş ve öğrencilerin matematiğe yönelik duydukları ilgiyi arttırdığını ifade etmiştir. Burns (2010)'un çalışmasında da matematik tarihi uygulamalarının öğrencilerin ilgilerini arttırdığı ortaya çıkmıştır. İlgi ve motivasyon öğrenmenin gerçekleşmesi için ön şartlardan ikisidir. Öğrencinin bir şeye ilgi duyması ilgi duyulan olgunun öğrenilme potansiyelini de ortaya çıkarır (Ocak \& Dönmez; 2010). Öğrencilerin matematiği sevmesi, matematik dersindeki öğrenme ortamı ile doğrudan ilişkilidir. Öğrenme ortamının eğlenceli, farklı duyulara hitap eden ve ilgi çekici olması öğrencilerin matematiği daha çok sevmelerini ve ona daha çok ilgi duymalarını sağlayacaktır (Baki, 2014; Fauvel, 1991). Şüphesiz ki matematik tarihinin de öğrencilerin matematiğe karşı ilgi ve motivasyonlarını arttırıı bir fonksiyonu vardır (Fried, 2007; Mann, 2011). Dolayısı ile bu değerlendirmelere bağlı olarak matematik tarihinin öğrencilerin matematiğe olan ilgilerini ve motivasyonlarını arttırdığı sonucuna varılabilir.

Kaygı faktörüne ilişkin, deney ve kontrol grubunun matematiğe yönelik kaygı son test puanları arasında istatistiksel olarak anlamlı düzeyde bir farklılık olmadığı görülmektedir. Bu verilere bağlı olarak öğrencilerin kaygı düzeylerinde istatistiksel olarak anlamlı derecede bir farklılık olmadığı anlaşılmaktadır. Bu değerlendirmeler ışı̆ında bu çalışmada matematik tarihinin matematik kaygısına bir etkisinin olmadığı sonucuna varılabilir. Bu sonuçlar Lim ve Chapman (2015) yapmış oldukları çalışmayla benzerlik göstermektedir. Matematik tarihinin öğrencilerin matematiğe tutumuna, kaygılarına, motivasyonlarına ve matematik başarısına etkisinin araştırıldığı çalışmada, deney ve kontrol grupları kaygı puanları arasında bir fark çıkmamıştır. Bu duruma sebep olarak ise yukarıda elde edilen sonuçlarda da ifade edildiği gibi kaygı ve zaman arasındaki ilişki üzerinde durulmuştur. Dede ve Dursun (2008) matematik kaygısının nedenlerini matematik başarısı, aile, öğretmen tutumu gibi etmenlerle ilişkilendirmişlerdir. Bu etmenlere bakıldığında kısa sürede değişim göstermeleri mümkün görülmemektedir. Dolayısı ile kaygının da değişimi bu kapsamda düşünülmelidir. Bu çalışmadan kaygı faktörü ile ilgili elde edilen sonuçlar bu düşünceler ışığında açıklanabilir. 
Çalışma faktörüne ilişkin bulgular incelendiğin deney ve kontrol gruplarının matematiğe yönelik çalışma son test puanları arasında istatistiksel olarak anlamlı düzeyde bir farklıık ortaya çıkmadığı görülmektedir. Deney ve kontrol grubunun çalışma puanları uygulama öncesinde benzer düzeyde iken uygulama sonrasında deney grubu çalışma puanlarının daha yüksek olmasına rağmen gruplar arası anlamlı bir fark ortaya çıkmamıştır. Fauvel (1991) matematik tarihinin avantajlarından bahsederken matematik tarihinin öğrencilerin araştırma yapmalarına olanak sağladığını belirtmiştir. Burns (2010) yapmış olduğu çalışmada ise matematik tarihinin öğrencilerin araştırma yapma ve çalışma isteklerini artıracağını artıracağı ifade etmiştir. Subaşı (2000) öğrencilerin kendilerini ruhsal olarak çalışma ortamına entegre edecek aktiviteleri yapmaları durumunda çalışma isteklerinde artış olacağını belirtmiştir. Literatürden matematik derslerinde matematik tarihi gibi aktivitelerin öğrencilerin çalışma isteklerini artıracağı söylenebilir.

Gereklilik faktörüne ilişkin bulgular incelendiğinde deney ve kontrol gruplarının matematiğe yönelik gereklilik son test puanları arasında istatistiksel olarak anlamlı düzeyde bir farklııı olduğu görülmektedir. Benzer sonuçlar (Carter, 2006; Cheung, 2014; Fadlelmula, 2015; Horton, 2011; Marshall, 2000) tarafından yapılan çalışmalarda da ortaya konulmuştur. Matematiğin insanlık için çok önemli bir uğraş olduğu, sadece okullardaki sınavlara ve zor bir ders olmasına bağlanmamalıdır. Matematiğin tarihin en ilkel dönemlerinden beri süregelen serüveni net ve anlaşilır bir şekilde ortaya konulmalı ve bu sürecin günümüze olan yansımaları kapsamlı bir şekilde ele alınmalıdır (NCTM, 2000). Dolayısı ile matematiğin gerekliliğinin ve öneminin anlaşılması için onun tarihinin öğrenilmesi ve öğretilmesi gerekmektedir (Baki, 2014; Fauvel, 1991; Mann, 2011). “Matematik neden gereklidir?" sorusunun bizdeki yansıması, tamamen gündelik yaşantılarımız doğrultusunda olduğunda matematiğin değerinin anlaşılması ve özümsenmesi tam manası ile mümkün olmayacaktır. Sonuç olarak, matematiğin tarihinin ve gelişim süreçlerinin bilinmesi, matematiğin gerekliliğinin anlaşılmasına önemli derecede katkı sağlayacaktır.

Matematiğe yönelik tutum toplam puanlarına bakıldığında deney ve kontrol grubunun son test puanları arasında anlamlı düzeyde bir farklılık olduğu görülmektedir. Sonuç olarak matematik tarihi uygulamalarının öğrencilerin matematiğe yönelik tutumlarını olumlu yönde etkilediği ifade edilebilir. İnsan çevresinde olup bitenlere bir anlam yükler ve bu anlamlar belli bir süre sonucunda tutum olarak ortaya çıkar (Yenilmez ve Özabacı; 2003). Olumlu bir tutumun ortaya çıkması için öğrencilerin zihinlerinde yer etmiş olan kavramlara olumlu anlamlar yüklemeleri gerekmektedir. Matematik dersini farklı ve eğlenceli hale getirip, olumlu bir tutum ortaya çıkarmak için matematik tarihi gibi yaklaşımlara derslerde yer verilebilir. Bu konuyu destekleyen çalışmalar (Cheung, 2014; Clark, 2012; Georgiou, 2010; Lim \& Chapman, 2015; Mcbride, 1974) mevcuttur. Mcbride (1974) tarafından yapılan çalışma sonuçlar itibari ile bu çalışma ile benzerlik göstermektedir. Bu çalışmada cebir dersini alan öğrencilere matematik tarihi destekli öğretim uygulanmış ve matematiğe yönelik tutumlarında olumlu yönde bir değişim tespit edilmiştir. Öğrenci başarıları arasında ise fark ortaya çıkmamıştır. İdikut (2007) ise bu sonuçlardan farklı olarak çalışmasında matematik tarihinin matematiğe yönelik tutuma bir etkisinin olmadığı, matematik başarısını ise artırdı̆̆ı sonucuna varmıştır. 
Fauvel (1991) matematik tarihinin matematiğe duyulan ilgi ve heyecanı arttıracağını belirtmiştir. Matematik tarihinin, öğrencilerde kavramsal çerçeve, çok kültürlü bir anlayış ve motivasyon algısı oluşmasında önemli etkisi vardır. Matematik tarihinden alınmış olan problemler üzerinde çalışmak, modern bir bakış açısının kazanılmasının yanı sıra, farklı çözüm yollarının da olabileceğini de görmeyi sağlayacaktır. Bu algının oluşması neticesinde de öğrencilerde matematiğe karşı olumlu bir tutum ortaya çıkacağı aşikardır.

Bu çalışmada matematik tarihine yönelik uygulamaların öğrencilerin matematiğe olan tutumlarına etkisi incelenmiştir. Matematik tutumu ilgi, kaygı, çalışma ve gereklilik olmak üzere dört faktör altında toplanmıştır. Faktörlere bağlı olarak öğrencilerin ilgi, gereklilik ve tutum toplam puanları arasında deney grubu lehine anlamlı bir fark ortaya çıkmıştır. Çalışma ve kaygı faktörleri arasında ise anlamlı bir fark ortaya çıkmamıştır. Bu sonuçlar dikkate alındığında matematik tarihinin öğrencilerin matematiğe olan tutumlarını olumlu yönde etkilediği sonucuna varılabilir. Bu kapsamda derslerde matematik tarihine yer verildiğinde bunun matematik öğretiminde önemli yansımaları olacaktır. Bu sonuçlar ışı̆̆ında öğretim programı ve ders kitaplarının yeniden değerlendirilmesi ve revize edilmesi gerekmektedir. Yine bu konuda öğretmenlerin ve öğretmen adaylarının yeterince bilgilendirilmesi ve matematik tarihi kullanımı noktasında teşvik edilmesi gerekmektedir. Ayrıca matematik tarihinin matematik öğretiminde kullanılması noktasında temel teşkil edecek ve yönlendirici olacak kaynakların yetersiz olmasından dolayı bu boşluğu dolduracak çalışmalar yapılmalıdır. Bu çalışma, öğrencilerin sınavlara hazırlanmasından dolayı çok uzun süre uygulanamamış ve sadece sayılar ve cebir konuları ile sınırlı tutulmuştur. Dolayısı ile bundan sonra yapılacak çalışmalarda uygulama süresi ve konular daha geniş bir yelpazede ele alındığında, daha açıklayıcı ve genelleştirilebilir sonuçların elde edilmesine katkı sağlayabilir.

\section{Kaynaklar}

Albayrak, Ö. (2011). Effects of history of mathematics integrated Instraction on mathematics selfefficacy and achievement (Yayımlanmamış doktora tezi). Boğaziçi Üniversitesi, İstanbul, Türkiye.

Alpaslan, M. (2011). Ilköğretim matematik öğretmen adaylarının matematik tarihi bilgileri ve matematik tarihinin matematik eğitiminde kullanımına yönelik tutum ve inanışları (Yayımlanmamış yüksek lisans tezi). ODTÜ Sosyal Bilimler Enstitüsü, Ankara, Türkiye.

Altun, M. (2006). Matematik öğretiminde gelişmeler. Uludağ Üniversitesi Eğitim Fakültesi Dergisi, 19(2), 223-238. http://dergipark.gov.tr/uefad/issue/16684/173367 adresinden edinilmiştir.

Altun, M. (2008). Matematik öğretimi. Bursa: Aktüel Yayınları.

Baki, A. (2008). Kuramdan uygulamaya matematik eğitimi. Ankara: Harf Eğitim Yayıncılık.

Baki, A. (2014). Matematik tarihi ve felsefesi. Ankara: Pegem Akademi Yayınclık.

Bayam, S.B. (2014). Matematik eğitiminde matematik tarihi gerekliliğinin felsefi temelleri ve gerçekçi matematik eğitiminde matematik tarihinin önemi. Dört Öge, 5, 233-244. 
Kani BAŞIBÜYÜK | Yasin SOYLU

Baykul, Y. (2009). Ilköğretimde matematik öğretimi 6-8. Sınılar. Ankara: Pegem Akademi Yayınları.

Bell, J.G. (1992). A history of mathematics class for middle school teachers (Unpublished doctoral dissertation). Illinois State University, USA.

Burns, B.A. (2010). Pre-service teachers' exposure to using the history of mathematics to enhance their teaching of high school mathematics. Issues in the Undergraduate Mathematics Preparation of School Teachers, 4, 1-9.

Büyüköztürk, Ş., Kılıç, E., Akgün, Ö. E., Karadeniz, Ş., ve Demirel, F. (2010). Bilimsel Araştırma Yöntemleri. (6. Baskı). Ankara: Pegem Akademi Yayınları.

Carter, D.B. (2006), The role of the history of mathematics in middle school (Unpublished master's thesis). East Tennessee State University faculty of the Department of Mathematics, Usa.

Cheung, W.S. (2014). The effect on students' mathematical beliefs by integrating history of mathematics in the classroom (Unpublished Doctoral Dissertation). The Chinese University of Hong Kong, China.

Clark, K.M., \& Thoo, J.B. (2014). Introduction to the special issue on the use of history of mathematics to enhance undergraduate mathematics instruction, PRIMUS: Problems, Resources, and Issues in Mathematics Undergraduate Studies, 24(8), 663-668. doi: 10.1080/10511970.2014.905511

Davis, P.J., Hersh, R., \& Marchisotto, E.A. (2011). The mathematical experience, study edition. Modern Birkhäuser Classics: Boston

Dede, Y., ve Dursun, Ş. (2008). İlköğretim II. kademe öğrencilerinin matematik kaygı düzeylerinin incelenmesi. Uludağ Üniversitesi Eğitim Fakültesi Dergisi,21(2), 295-312. http://dergipark.gov.tr/uefad/issue/16688/173418 adresinden edinilmiştir.

Despeaux (2014). Collective research projects in the history of mathematics classroom. PRIMUS: Problems, Resources, and Issues in Mathematics Undergraduate Studies, 24(8), 684-697.

Ernest, P. (2004). The philosophy of mathematics education. London: Routledge/ Falmer

Ersoy, E., ve Öksüz, C. (2016). İlkokul 4. sınıflarda matematik tarihi kullanımının öğrenciler üzerindeki etkileri. Illköğretim Online, 15(2), 408-420. doi: 10.17051/io.2016.16857

Fadlelmula, F.K. (2015. Pre-service teachers' point of views about learning history of mathematics: a case study in Turkey. Journal of the British Society for the History of Mathematics, 30(3), 243252. doi: $10.1080 / 17498430.2015 .1035585$

Fauvel, J. (1991). Using history in mathematics education. For the Learning of Mathematics, 11(2), 3-6. Retrieved from http://www.jstor.org/stable/40248010 
Fried, M.N. (2007). Didactics and history of mathematics: knowledge and self-knowledge. Educational Studies in Mathematics, 66(2), 203-223. doi: 10.1007/s10649-006-90255

Furinghetti, F. (2004). History and mathematics education: a look around the world with particular reference to Italy. Mediterranean Journal for Research in Mathematics Education, 3, 1-19.

Georgiou, I. (2010). A week with secondary mathematics through history and culture. Proceedings of the British Society for Research into Learning Mathematics, 30(3), 43-48.

Goodwin, D.M. (2007). Exploring the relationship between high school teachers mathematıcs history knowledge and their Images of mathematics (Unpublished Doctoral Dissertation). University of Massachusetts Lowell, USA.

Gönülateş, F.O. (2004). Prospective teachers' views on the integration of history of mathematics in mathematics courses (Unpublished Master's Thesis). Boğaziçi Üniversitesi, İstanbul, Türkiye.

Guillemette, D. (2017). History of mathematics in secondary school teachers' training: towards a nonviolent mathematics education. Educational Studies in Mathematics, 96(3), 349-365. doi: 10.1007/s10649-017-9774-3

Gürsoy, K. (2010). ilköğretim matematik öğretmen adaylarının matematik tarihinin matematik öğretiminde kullanılmasına ilişkin inanç ve tutumlarının incelenmesi (Yayınlanmamış Yüksek Lisans Tezi). Karadeniz Teknik Üniversitesi, Trabzon. Türkiye.

Harverhals, N., \& Matt, R. (2010). The history of mathematics as a pedagogical tool: teaching the integral of the secant via mercator's projection. The Montana Mathematics Enthusiast, 7, 339-368. Retrieved from https://scholarworks.umt.edu/tme/vol7/iss2/12

Heiede, T. (1992). Why teach history of mathematics? The Mathematical Gazette, 76(475), 151157.

Horton, L.B. (2011). High school teachers' perceptions of the inclusion of history of mathematics in the classroom (Unpublished Doctoral Dissertation). Mathematics and Science Education University of Massachusetts Lowell, USA.

İdikurt, N. (2007). Matematik öğretiminde tarihten yararlanmanın öğrencilerin matematiğe yönelik tutumlarına ve matematik başarılarına etkisi (Yayınlanmamış Yüksek Lisans Tezi). Yüzüncü Yıl Üniversitesi, Van, Türkiye.

Lewis, K.C. (2016). Ethnomathematics meets history of mathematics: A case study (Unpublished Doctoral dissertation). Texas A\&M University, USA.

Lim, S.Y., \& Chapman, E. (2015). Effects of using history as a tool to teach mathematics on students' attitudes, anxiety, motivation and achievement in grade 11 classrooms. Educational Studies in Mathematics, 90, 189-212. doi: 10.1007/s10649-015-9620-4 
Kani BAŞIBÜYÜK | Yasin SOYLU

Mann, T. (2011). History of mathematics and history of science. ISIS: The History of Science Society, 102(3), 518-526. doi: 10.1086/661626

Marshall, G.L. (2000). Using history of mathematics to improve secondary students' attitudes toward mathematics (Unpublished doctoral dissertation). Illinois State University, USA.

Mcbride, C.C. (1974). The effects of history of mathematics on attitudes toward mathematics of college algebra students (Unpublished doctoral dissertation). Texsas A\&M University. USA.

Metin, M. (Ed.) (2015). Kuramdan uygulamaya eğitimde bilimsel araştırma yöntemleri, Ankara: Pegem Akademi Yayınları.

Miller, C.C. (2002). Teaching the history of mathematics: a trial by fire. Problems, Resources, and Issues in Mathematics Undergraduate Studies, 12(4), 334-346. doi: $10.1080 / 10511970208984039$

National Council of Teachers of Mathematics. (2000). Overview of principles and standards for school mathematics. Retrieved December 13, 2015, from http://www.nctm.org/standards/content.aspx?id=16909.

Ocak, G., ve Dönmez, S. (2010). İlköğretim 4. ve 5. sınıf öğrencilerinin matematik etkinliklerine yönelik tutum ölçeği geliştirme. Kuramsal Eğitimbilim Dergisi,3(2). 69-82. http://dergipark.gov.tr/akukeg/issue/29341/313980 adresinden edinilmiştir.

Önal, N. (2013). Ortaokul öğrencilerinin matematik tutumlarına yönelik ölçek geliştirme çalışması, Illkögretim Online, 12(4), 938-948. http://dergipark.ulakbim.gov.tr/ilkonline/article/view/5000037735/5000036593 adresinden edinilmiştir.

Pepe, L., \& Guerraggio, A. (2017). Why do we need the history of mathematical teaching?. Lettera Matematica, 5(3), 245-251. Doi: 10.1007/s40329-017-0193-1

Saban, A. (2005). Çoklu zeka teorisi ve eğitim. Ankara: Nobel Yayın Dağıtım.

Siu, M.K. (2007). No, I don't use history of mathematics in my class. Why?. In F. Furinghetti, S. Kaijser, and C. Tzanakis (Eds.), Proceedings of the History and Pedagogy of Mathematics 2004 \& European Summer University 4 (pp. 268-277). Uppsala: Uppsala University.

Skemp, R.E. (1986). The psychology of learning mathematics. UK: Penguin Books.

Subaşı, G. (2000). Verimli ders çalışma alışkanlıkları eğitiminin akademik başarı, akademik benlik kavramı ve çalışma alışkanlıklarına etkisi. Eğitim ve Bilim, 25(117), 50-56.

Sullivan, K.M. (2000). Pre-service secondary mathematic teachers' attitudes about thehistory of mathematics (Unpublished master's thesis). Nevada University, Las Vegas, USA. 
Yenilmez, K., ve Özabacı, N.Ş. (2003). Yatılı öğretmen okulu öğrencilerinin matematik ile ilgili tutumları ve matematik kaygı düzeyleri arasındaki ilişki üzerine bir araştırma. Pamukkale Üniversitesi Eğitim Fakültesi Dergisi, 14(14), 132-146. http://dergipark.gov.tr/download/article-file/114804 adresinden edinilmiştir.

Yevdokimov, 0. (2007). Using the history of mathematics for mentoring gifted students: Notes for teachers. 21st Biennial Conference of the Australian Association

Yıldırım, A. ve Şimşek, H. (2011). Sosyal bilimlerde nitel araştırma yöntemleri (8. Baskı). Ankara: Seçkin Yayıncılık.

Yıldız, C. (2013). Ortaokul matematik öğretmenlerinin matematik tarihini derslerinde kullanma durumlarının incelenmesi: HiE'den yansımalar (Yayımlanmamış yüksek lisans tezi). Karadeniz Teknik Üniversitesi, Trabzon, Türkiye. 